\title{
Why Do Startups Succeed or Fail: Teams, Ideas or Execution?
}

\author{
Chuck Sacco (Drexel University)
}

KEYWORDS: Entrepreneurship, Teaching Methods, Startups, Team Development.

Startups succeed or fail for a variety of reasons: no market need, not the right team, timing, running out of cash, premature scaling and more. It is important for students to understand this so that they can anticipate potential challenges for companies that they may start and so they can develop risk-mitigation strategies to potentially reduce the likelihood of failure.

It is difficult for students to understand the reasons for startup success and failure without actually experiencing it. So, the purpose of this simulation-based exercise is to help students better understand some of the possible root causes of startup failure and to see that several factors can be involved in influencing a startup's destiny.

For this exercise, we zero in on analyzing three factors that can determine a startup's success or failure: the quality and make-up of the team, the innovativeness and potential of the idea, and ability of the team to execute and communicate their value proposition to others.

Very purposely, the teams are limited to a fixed set of resources (time, materials and team). This helps simulate the real constraints of a startup. It is also purposely setup so that every team uses the same materials to reduce variability and make it easier for teams to compare and contrast their respective efforts.

\section{ADVANCE PREPARATION}

Below is a picture of the materials that the instructor provided to each team. The students were shown the materials a week before the kickoff of the exercise but were not allowed to touch or use the materials in any way. The idea was to give students the opportunity to individually start thinking about potential ideas but not give them the complete set of tools to ensure some level of team spontaneity.

While it is certainly possible to use any variety of materials, the materials used for this exercise, obtained in an arts supply store, included:

- Rubber bands

- Wooden wheels

- Pipe cleaners

- A variety of small wooden boards in various shapes and sizes

- Springs

- Wire

\section{LEARNING OBJECTIVES}

This exercise has these primary learning objectives for students:

1. Create a new idea based on a defined and constrained set of materials

2. Build and present their idea

3. Analyze their team's performance

4. Evaluate their team's performance through the lens of success and failure 


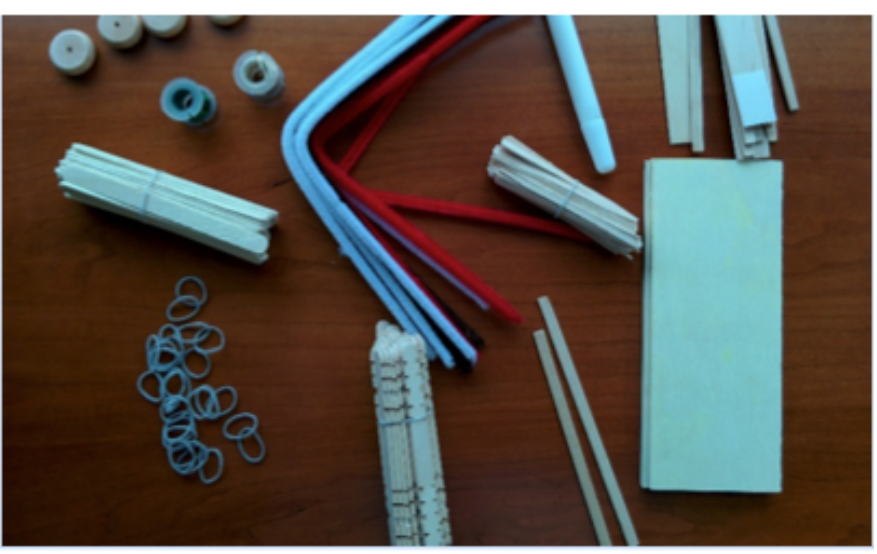

It may also be helpful to plan for a few "curveballs" in the plan. You might consider changing the schedule, shortening the available time for exercise elements, shuffling team members, pulling team members out for a period of time or removing some of the materials from the available set. The idea here is to help students to learn to anticipate that not everything will go according to plan.

\section{EXERCISE DETAILS}

The exercise is held over several weeks, although it can be adjusted as needed to accommodate class schedules. One reason for spreading out the individual elements is to allow the instructor to introduce additional educational topics during the weeks as well as give teams the opportunity to continue some work on the exercise outside of the classroom.

The following is the schedule of activities:

\section{Week 1: Individual idea development}

- Class is provided pictures of the materials; alternatively, the actual materials are laid out so the students can easily see what's available

- Individually, students are tasked to develop some ideas based on available materials

- They can only look at the materials (no touching)

\section{Week 2: Individual idea pitch and team}

\section{formation}

- Individual students present their idea(s) to the entire class in a one-minute pitch; the purpose is for students to learn about the other ideas and potentially want to team up with other students with similar or complementary ideas.

- Students are then asked to form teams (3-4 per team).

- They then must negotiate which of the individual ideas they will use; they are welcome to combine ideas or come up with entirely new ones.

\section{Week 3: Develop action plan}

- The purpose of this part of the exercise is for them to collaborate as teammates. They need to come up with a plan based on a stated amount of time they will have to develop their idea. They are provided access to the materials and their plans are reviewed with the instructor.

\section{Week 4: Idea execution}

- Students must execute on their idea and build something with a one-hour time limit.

- They are then asked at the end of an hour to start preparing a presentation. This should include a name, team information, the idea, its value to the user/customer. They are also asked to address what worked and what didn't as a team, the quality of the idea and their ability to execute.

\section{Week 5}

- Each team presents to the rest of the class.

- Class discussion on each presentation: What do they think contributed more to the perceived success or failure of the effort: ideas, team or execution?

\section{POST-EXERCISE DISCUSSION and REPORT}

The following discussion and report were completed by the students:

- Peer evaluation on the quality of their 
teammates' efforts

- Self-evaluation report on what worked and what didn't as it relates to the team, the initial idea and their execution

- Questions that the students are asked to address include:

- Did they have a good idea that failed on execution?

- Did they have good or bad team dynamics?

- Was the idea not so good but presented and executed well?

- Overall, how did the exercise help them better understand the dynamics of a startup and the potential root causes of failure?

\section{STUDENT OUTCOME MEASUREMENT}

Following the learning objectives defined above, the exercise outcome measurement was defined as:

\begin{tabular}{|l|l|l|l|l|}
\hline & $\begin{array}{l}\text { Novice } \\
(<50 \%)\end{array}$ & $\begin{array}{l}\text { Competent } \\
(50-80 \%)\end{array}$ & $\begin{array}{l}\text { Proficient } \\
(80-90 \%)\end{array}$ & $\begin{array}{l}\text { Excellent } \\
(>90 \%)\end{array}$ \\
\hline Quality of the idea generation efforts & & & & \\
\hline Ability to build on their idea using materials & & & & \\
\hline Quality of team presentation & & & & \\
\hline Team performance analysis & & & & \\
\hline Success/failure analysis & & & & \\
\hline
\end{tabular}

\section{EXERCISE RESULTS}

This exercise has been run in two different classes. The students seemed to enjoy the effort and gained a good understanding of the variety of ways that a new idea can be successful or fail. They are also better able to distinguish between the quality of the idea and the quality of the team and understand how effective communication is critical to success.

\section{IDEAS FOR THE FUTURE}

This exercise can be adapted and improved in several ways. One thought is to have teams built randomly vs. having self-selected teams.

\section{REFERENCES}

CB Insights (2014). Top 20 Reasons Startup Fail. Retrieved from www.cbinsights.com/research/startupfailure-reasons-top (http://www.cbinsights.com/research/startup-failurereasons-top)

Marmer, M., Herrmann, B.L., Dogrultan, E., Berman, R.,
Eesley, C., Blank, S.: Startup Genome Report Extra: Premature Scaling. Technical report, Startup Genome (2011)

Read more on this topic: "After the Big Idea: Entrepreneurial Success Through High-Performance Startup Teams" (https://eiexchange.com/content/22-after-the-big-idea-e ntrepreneurial-success-through-high-performance-startup-teams? search=high\%20performance\%20startup $\% 2$ Oteams)

Additional Search Terms: entrepreneurship courses, teaching ideas, teaching resources, classroom ideas, entrepreneurship classes, business schools, business school classes, entrepreneurship students, professors 